\title{
REFERENTES CONCEPTUALES
}

Respecto a la Corte Constitucional colombiana, en esta obra se hace un análisis del precedente jurisprudencial de esta Alta Corporación en relación con las áreas de acción estatal y los principios de justicia transicional: verdad, justicia, reparación y garantías de no repetición, para lograr una reparación integral a las víctimas del conflicto armado, lo cual se desarrolla con base en veinte (20) sentencias distribuidas entre 2010 y 2014.

Se analizó la Sentencia C-936 de 2010, donde se conoció la demanda de inconstitucionalidad por vulnerar los derechos de las víctimas, desconocer el deber del Estado de investigar y juzgar las violaciones de los derechos humanos y sobrepasar los límites del principio de oportunidad. Se reconoce, entonces, la importancia de garantizar estos principios de la mano del bloque de constitucionalidad, dado que la jurisprudencia colombiana comparte el alcance en cuanto a esto del derecho internacional.

Así, es obligación del Estado respetar y garantizar el ejercicio de los derechos humanos, al igual que investigar y juzgar las violaciones de los derechos humanos cometidas dentro de su territorio y proteger los derechos de las víctimas. Por ello, la Corte determina que las versiones de los desmovilizados pueden servir como prueba judicial contra terceros, dado que de esta forma se pueden garantizar los derechos a las víctimas. Se parte, entonces, de "los eventos en los que un sujeto resulta personalmente afectado como resultado de hechos $u$ acciones que 
directamente hubieren recaído sobre otras personas"1, para así definir el concepto de víctima y la posibilidad de que esta sea entendida como colectiva.

Se define como víctima a cualquier persona que ha sufrido daño como consecuencia de los hechos previstos en el inciso 1 de la Sentencia C-052 de 2012, "por hechos ocurridos [...] como consecuencia de infracciones al Derecho Internacional Humanitario o de violaciones graves y manifiestas a las normas internacionales de Derechos Humanos, ocurridas con ocasión del conflicto armado interno".2

Ahora bien, el concepto de despojo se debe abordar desde el área de acción estatal hacia la restitución tanto de las víctimas que han sido despojadas como de las que fueron obligadas a abandonar sus propiedades. De igual forma, es importante considerar el concepto de victimizante y su actuar, para desarrollar esto en un contexto más fuerte. Según lo anterior, cuando se habla de restitución, solo tiene lugar respecto de bienes inmuebles; la reparación en relación con los bienes muebles se ve materializada con la indemnización, del mismo modo que ocurre con quienes ostentan la calidad de tenedor.

A continuación se resumen los conceptos tomados para formar la estructura que se presenta en esta obra.

\section{Justicia}

a. La obligación del Estado de prevenir las graves violaciones de derechos humanos, especialmente cuando se trata de violaciones masivas, continuas y sistemáticas como el desplazamiento forzado interno.

b. La obligación del Estado de luchar contra la impunidad.

c. La obligación de establecer mecanismos de acceso ágil, oportuno, pronto y eficaz a la justicia para la protección judicial efectiva de los derechos de las víctimas de delitos. En este sentido, se fija la obligación del Estado de diseñar y garantizar recursos judiciales efectivos para que las personas afectadas puedan ser oídas, y de impulsar las investigaciones y hacer valer los intereses de las víctimas en el juicio. 
d. El deber de investigar, procesar y sancionar judicialmente a los responsables de graves violaciones de derechos humanos, como el desplazamiento forzado.

e. El respeto del debido proceso y de que las reglas de procedimiento se establezcan con respeto de este.

f. La obligación de establecer plazos razonables para los procesos judiciales, teniendo en cuenta que los términos desproporcionadamente reducidos pueden dar lugar a la denegación del derecho a la justicia de las víctimas y a la no obtención de una justa reparación.

g. El deber de iniciar ex oficio las investigaciones en casos de graves violaciones contra los derechos humanos.

h. El mandato constitucional de velar por que los mecanismos judiciales internos, tanto de justicia ordinaria como de procesos de transición hacia la paz, como amnistías e indultos, no conduzcan a la impunidad y al ocultamiento de la verdad.

i. El establecimiento de limitantes y restricciones derivadas de los derechos de las víctimas, frente a figuras de seguridad jurídica tales como el non bis in idem y la prescriptibilidad de la acción penal y de las penas, en casos de violaciones protuberantes a los derechos humanos, el Derecho Internacional Humanitario y el Derecho Internacional de los Derechos Humanos.

j. La determinación de límites frente a figuras de exclusión de responsabilidad penal o de disminución de las penas en procesos de transición, por cuanto no es admisible la exoneración de los responsables de graves violaciones a los derechos humanos y al Derecho Internacional Humanitario; por tanto, se configura el deber de juzgar y condenar a penas adecuadas y proporcionales a los responsables de los crímenes investigados. Esta regla, como lo ha señalado la Corte, solo puede tener excepciones en procesos de justicia transicional en los cuales se investiguen a fondo las violaciones de derechos humanos y se restablezcan los derechos mínimos de las víctimas a la verdad y a la reparación integral, al igual que se diseñen medidas de no repetición destinadas a evitar que los crímenes se repitan.

k. La legitimidad de la víctima y de la sociedad en casos de graves violaciones de los derechos humanos y del Derecho Internacional Humanitario, 
para hacerse parte civil dentro de los procesos penales con el fin de obtener la verdad y la reparación del daño.

1. La importancia de la participación de las víctimas dentro del proceso penal, de conformidad con los artículos 29 y 229 de la Constitución, y 8 y 25 de la Convención Interamericana sobre Derechos Humanos.

m. La garantía indispensable del derecho a la justicia para que se garantice asimismo el derecho a la verdad y a la reparación de las víctimas.

\section{Verdad}

a. El derecho a la verdad se encuentra consagrado en los principios 1 a 4 de los Principios para la protección y promoción de los derechos humanos mediante la lucha contra la impunidad, y encuentra su fundamento en el principio de dignidad humana, en el deber de memoria histórica y de recordar y en el derecho al buen nombre y a la imagen.

b. Las víctimas y los perjudicados por graves violaciones de derechos humanos tienen el derecho inalienable a saber la verdad de lo ocurrido. Este derecho se encuentra en cabeza de las víctimas, de sus familiares y de la sociedad en su conjunto; por tanto, apareja una dimensión individual y una colectiva.

c. La dimensión individual del derecho a la verdad implica que las víctimas y sus familiares conozcan la verdad sobre los hechos, los responsables y las consecuencias de lo sucedido. Esto apareja, por tanto, el derecho a conocer la autoría del crimen, los motivos y las circunstancias de tiempo, modo y lugar en que ocurrieron los hechos delictivos, y finalmente, el patrón criminal que marca la comisión de los hechos criminales. Esto último implica el derecho a conocer si el delito que se investiga constituye una grave violación a los derechos humanos, un crimen de guerra o un crimen de lesa humanidad.

d. La dimensión colectiva del derecho a la verdad, por su parte, significa que la sociedad debe conocer la realidad de lo sucedido, su propia historia, la posibilidad de elaborar un relato colectivo a través de la divulgación pública de los resultados de las investigaciones, e implica la obligación de contar con una "memoria pública" sobre los resultados de estas investigaciones sobre graves violaciones de derechos humanos. 
e. El derecho a la verdad constituye un derecho imprescriptible que puede y debe ser garantizado en todo tiempo; con la garantía del derecho a la verdad se busca la coincidencia entre la verdad procesal y la verdad real. Este derecho se encuentra intrínsecamente relacionado y conectado con el derecho a la justicia y a la reparación. Así, el derecho a la verdad se encuentra vinculado con el derecho de acceso a la justicia, ya que la verdad solo es posible si se proscribe la impunidad y se garantiza, a través de investigaciones serias, responsables, imparciales, integrales y sistemáticas por parte del Estado, el consecuente esclarecimiento de los hechos y la correspondiente sanción.

f. El derecho a la verdad se encuentra vinculado con el derecho a la reparación, ya que el conocimiento de lo sucedido para las víctimas y sus familiares constituye un medio de reparación.

g. Los familiares de las personas desaparecidas tienen derecho a conocer el destino de los desaparecidos y el estado y resultado de las investigaciones oficiales. En este sentido, el derecho a conocer el paradero de las personas desaparecidas o secuestradas se encuentra amparado en el derecho del familiar o allegado de la víctima a no ser objeto de tratos crueles, inhumanos o degradantes, y debe ser satisfecho, incluso, si no existen procesos penales en contra de los presuntos responsables ("por muerte, indeterminación o cualquier otra causa").

h. Finalmente, en cuanto al derecho a la verdad, la Corte resalta no solo la obligación del Estado de adelantar investigaciones criminales con el fin de esclarecer la responsabilidad penal individual y la verdad de los hechos, sino también la importancia de mecanismos alternativos de reconstrucción de la verdad histórica, como comisiones de la verdad de carácter administrativo, las cuales, en casos de vulneraciones masivas y sistemáticas de los derechos humanos, deben servir a los fines constitucionales antes mencionados

\section{Reparación}

a. El reconocimiento expreso del derecho a la reparación del daño causado que les asiste a las personas que han sido objeto de violaciones de 
derechos humanos. Este, por tanto, es un derecho internacional y constitucional de las víctimas, como en el caso del desplazamiento forzado.

b. El derecho a la reparación integral y las medidas que este derecho incluye se encuentran regulados por el derecho internacional en todos sus aspectos: alcance, naturaleza, modalidades y determinación de los beneficiarios; aspectos que no pueden ser desconocidos y deben ser respetados por los Estados obligados.

c. El derecho a la reparación de las víctimas es integral, en la medida en que se deben adoptar distintas medidas determinadas no solo por la justicia distributiva, sino también por la justicia restaurativa, en cuanto se trata de la dignificación y restauración plena del goce efectivo de los derechos fundamentales de las víctimas.

d. Las obligaciones de reparación incluyen, en principio y de manera preferente, la restitución plena (restitutio in integrum), que hace referencia al restablecimiento de la víctima a la situación anterior al hecho de la violación, entendida esta como una situación de garantía de sus derechos fundamentales; dentro de estas medidas se incluye la restitución de las tierras usurpadas o despojadas a las víctimas.

e. De no ser posible tal restablecimiento pleno, es procedente la compensación a través de medidas como la indemnización pecuniaria por el daño causado.

f. La reparación integral incluye, además de la restitución y de la compensación, una serie de medidas tales como la rehabilitación, la satisfacción y las garantías de no repetición. Así, el derecho a la reparación integral supone el derecho a la restitución de los derechos y bienes jurídicos y materiales de los cuales ha sido despojada la víctima; la indemnización de los perjuicios; la rehabilitación por el daño causado; medidas simbólicas destinadas a la reivindicación de la memoria y de la dignidad de las víctimas; así como medidas de no repetición para garantizar que las organizaciones que perpetraron los crímenes investigados sean desmontadas y las estructuras que permitieron su comisión sean removidas, a fin de evitar que las vulneraciones continuas, masivas y sistemáticas de derechos se repitan. 
g. La reparación integral a las víctimas de graves violaciones a los derechos humanos tiene tanto una dimensión individual como colectiva.

h. En su dimensión individual, la reparación incluye medidas tales como la restitución, la indemnización y la readaptación o rehabilitación.

i. En su dimensión colectiva, la reparación se obtiene también a través de medidas de satisfacción y carácter simbólico, o de medidas que se proyecten a la comunidad.

j. Una medida importante de reparación integral es el reconocimiento público del crimen cometido y el reproche de tal actuación. En efecto, como ya lo ha reconocido la Corte Constitucional, la víctima tiene derecho a que los actos criminales sean reconocidos y a que su dignidad sea restaurada a partir del reproche público de dichos actos. Por consiguiente, una manera de vulnerar de nuevo sus derechos es la actitud dirigida a desconocer, ocultar, mentir, minimizar o justificar los crímenes cometidos.

k. El derecho a la reparación desborda el campo de la reparación económica e incluye, además de las medidas ya mencionadas, el derecho a la verdad y a que se haga justicia. En este sentido, el derecho a la reparación incluye tanto medidas destinadas a la satisfacción de la verdad y de la memoria histórica como medidas destinadas a que se haga justicia, se investigue y se sancione a los responsables. Por tanto, la Corte ha evidenciado el derecho a la reparación como un derecho complejo, por cuanto se encuentra en una relación de conexidad e interdependencia con los derechos a la verdad y a la justicia, de manera que no es posible garantizar la reparación sin verdad y sin justicia

1. La reparación integral a las víctimas debe diferenciarse de la asistencia y servicios sociales y de la ayuda humanitaria brindada por parte del Estado; por tanto, estos no pueden confundirse entre sí, en razón a que difieren en su naturaleza, carácter y finalidad. Mientras que los servicios sociales tienen su título en derechos sociales y se prestan de manera ordinaria con el fin de garantizar dichos derechos sociales, prestacionales o políticas públicas relativas a derechos de vivienda, educación y salud, y mientras la asistencia humanitaria la ofrece el Estado en caso de desastres, la reparación, en cambio, tiene como título la comisión de un ilícito, la ocurrencia de un daño antijurídico y la grave vulneración de los derechos 
humanos, razón por la cual no se puede sustituirlas o asimilarlas, aunque una misma entidad pública sea responsable de cumplir con esas funciones, so pena de vulnerar el derecho a la reparación.

m. La necesaria articulación y complementariedad de las distintas políticas públicas, pese a la clara diferenciación que debe existir entre los servicios sociales del Estado, las acciones de atención humanitaria y las medidas de reparación integral. De esta manera, el Estado debe garantizar todas las medidas, tanto de atención como de reparación a la población desplazada, hasta el restablecimiento total y goce efectivo de sus derechos.

Se estableció que el fallo se aplicará a casos análogos y que dichos efectos cobijarán todas las solicitudes de indemnización administrativa realizadas por víctimas de desplazamiento forzado, en los siguientes casos:

a. Si hubiesen sido presentadas con anterioridad a la Ley 1448 del 2011.

b. Si hubiesen sido negadas por el Departamento para la Prosperidad Social sin la debida observancia.

c. Si hubiesen presentado acciones de tutela por los motivos mencionados.

Es importante tener en cuenta que la reparación integral a las víctimas del conflicto armado debe diferenciarse de la ayuda humanitaria, debido a que aquella no concluye con la indemnización pecuniaria, sino que requiere de otras condiciones:

(i) La rehabilitación por el daño causado; (ii) programas simbólicos destinados a la reivindicación de la memoria y de la dignidad de las víctimas; así como (iii) medidas de no repetición para garantizar que las organizaciones que perpetraron los crímenes investigados sean desmontadas y las estructuras que permitieron su comisión, removidas, a fin de evitar que las vulneraciones continuas, masivas y sistemáticas de derechos se repitan. ${ }^{3}$

La Corte insiste en que la reparación integral solo tiene lugar en la medida en que sean garantizados en su totalidad los derechos fundamentales de las víctimas, como consecuencia de la estrecha relación entre unos y otros. Siguiendo esta 
línea, la Corte transcribe las reglas para conceder vía tutela condenas en abstracto, así como las vías para obtener la reparación integral.

Se consideraron algunas consecuencias derivadas de los derechos de las víctimas a la verdad, la justicia y la reparación:

a. Verdad. Implica conocer lo que sucedió y se halla ligada a la dignidad humana en cuanto refiere la memoria e imagen de la víctima. Este derecho envuelve garantías como: (i) el derecho inalienable a la verdad, (ii) el deber de recordar y (iii) el derecho de las víctimas a saber.

b. Justicia. Se orienta a la no impunidad e implica unas garantías como: (i) el deber del Estado de investigar y sancionar adecuadamente a los autores y partícipes de los delitos, (ii) el derecho de las víctimas a un recurso judicial efectivo y (iii) el deber de respetar en todos los juicios las reglas del debido proceso.

c. Reparación. Su dimensión como compensación económica es dejada de lado al afirmarse que se compone de medidas individuales, a saber: (i) restitución, (ii) indemnización, (iii) rehabilitación, (iv) satisfacción y (v) garantía de no repetición. También se compone de otros recursos colectivos, que envuelvan garantías como "medidas de satisfacción de alcance general como la adopción de medidas encaminadas a restaurar, indemnizar o readaptar los derechos de las colectividades o comunidades directamente afectadas por las violaciones ocurridas".

En cuanto a la inmediatez, es viable la acción de tutela aun cuando hubiese transcurrido bastante tiempo entre la ocurrencia del daño antijurídico y la presentación de esta, siempre y cuando:

a. Se demuestre la continuidad de la vulneración en el tiempo.

b. La exigencia de acudir a un juez se constituya como una carga desproporcionada para la víctima, atendiendo a sus condiciones particulares: indefensión, incapacidad física, minoría de edad, etc.

Se destaca la diferencia entre la reparación por vía administrativa y la judicial (penal y contencioso administrativo) dentro de un régimen de transición de justicia y paz. 
Ahora bien, en cuanto al Consejo de Estado, se hace el análisis del precedente jurisprudencial con respecto a las cuatro áreas de acción estatal para la reparación integral de las víctimas del conflicto armado en el marco de la justicia transicional. En coherencia con los supuestos metodológicos referidos inicialmente, este análisis se compone de veinte (20) sentencias distribuidas entre 2010 y 2015. Se hace un breve desarrollo de la consagración constitucional de la tutela como un mecanismo preferente y sumario para la defensa de los derechos fundamentales, subsidiario en caso de no existir otro medio judicial para la defensa del derecho que se invoca y transitorio en cuanto con esta se pretenda conjurar un perjuicio irremediable de los derechos objeto de amparo. El Consejo de Estado reitera:

a. El derecho a la reparación integral de las víctimas no se reduce a la indemnización de carácter económico, sino que abarca la materialización de las áreas de acción estatal.

b. El cuanto a la protección de los derechos de las víctimas, el operador jurídico está facultado para amparar incluso aquellos no invocados en la solicitud.

El Consejo de Estado desarrolla los componentes de las dos etapas finales e indica, de acuerdo con la normatividad vigente, los elementos que las integran y las entidades responsables de garantizarlos:

a. Salud. "(i) A la EPS del régimen subsidiado o contributivo a la que se encuentre afiliada, en caso de que esté asegurada; (ii) a la Secretaría de Salud de (cada ciudad), como entidad receptora, en caso de que no esté afiliada a ningún régimen, y (iii) a las instituciones públicas o privadas de salud en forma obligatoria les corresponde brindar la atención inicial de urgencias (Decreto 2131 de 2003)".

b. Educación. "Corresponde asegurarla a la Secretaría de Educación de (cada ciudad), como entidad territorial receptora, y en los niveles de preescolar, básica y media (Decreto 2562 de 2001)".

c. Acceso y tenencia de tierras para fines productivos. "Compete garantizarla al Incoder (Decreto 2007 de 2001 y numeral 1 del artículo 19 de la Ley 387 de 1997)". 
d. Proyectos productivos y capacitación laboral. "Corresponde promover el ingreso a estos programas, en el ámbito rural, al Ministerio de Agricultura y Desarrollo Rural, al Incoder, a Finagro, al Fondo Agropecuario de Garantías y al Banco Agrario; y en el ámbito urbano, al Ministerio de Industria, Comercio y Turismo, Fomipyme, al Fondo Nacional de Garantías y a Bancóldex, cada uno en el ámbito de sus competencias. Y al SENA le corresponde ofrecer la capacitación laboral (Decreto 250 de 2005 y artículo 19 numeral 11 de la Ley 387 de 1997)".

e. Vivienda. "La asignación de subsidios de vivienda urbana compete a Fonvivienda (Decreto 951 de 2001 y artículo 19, numeral 14 de la Ley 387 de 1997), y de vivienda de interés social rural al Ministerio de Agricultura y Desarrollo Rural (Decreto 2675 de 2005, artículo 10). Para ello, el hogar desplazado debe presentar postulación dentro de las convocatorias abiertas por esas entidades".

f. Reparación administrativa. "A Acción Social le corresponde recibir las solicitudes de los desplazados para acceder al Programa de Reparación Individual por Vía Administrativa para las Víctimas de los Grupos Armados Organizados al Margen de la Ley, y presentar un estudio técnico ante el Comité de Reparaciones Administrativas, el cual debe decidir si reconoce las medidas de reparación (Decreto 1290 de 2008)". ${ }^{4}$

En concreto, se hace mención a tres situaciones:

a. Las características fijadas por la Corte Constitucional respecto del derecho fundamental de tutela y los eventos en que este puede considerarse vulnerado, además de su especial importancia en el caso de las víctimas del conflicto armado.

b. Cuando se decide sobre la falta de legitimación objetada por la Dirección de Justicia Transicional del Ministerio de Justicia y del Derecho y se encuentra que la excepción no tiene lugar, debido a que entre sus obligaciones está la de dar respuesta a las peticiones relacionadas con el reconocimiento de la calidad de víctimas y el otorgamiento de prerrogativas orientadas a la reparación de ellas.

4 Consejo de Estado, Sentencia del 30 de junio de 2011, radicado 76001-23-31-000-2011-00575-01(AC), C. P. Susana Buitrago Valencia. 
c. Cuando se confirma la sentencia tutelando en derecho fundamental de petición, y se comprende que si bien existe vulneración de los demás derechos invocados, esta deviene de la no respuesta a la petición, por lo que con la tutela del último se entiende conjurada la violación de los demás.

El Consejo de Estado enuncia las reglas que deben ser tenidas en cuenta para valorar este tipo de prueba, a saber:

a. Calidades personales de quien rinde el testimonio.

b. Circunstancias en las que conocieron los hechos testificados.

c. La fuente que transfirió el conocimiento de lo testificado.

d. La clase de testimonio "de oídas", que pueden ser de primer grado en adelante, es decir, una persona conoce y relata los hechos, que a su vez conoce a quien escucha y los transmite a otro, y así sucesivamente; con ello, la información que poseen los grados distantes se convierte en simples rumores.

Con el propósito de reparar integralmente la víctima del caso concreto, y atendiendo a la imposibilidad de resarcir un daño antijurídico como la muerte en términos exclusivamente económicos, el operador jurídico concedió medidas no pecuniarias como reanudar la investigación penal de los hechos y la divulgación de determinados apartados del presente fallo, indicando los nombres de los responsables. Estas medidas están orientadas a garantizar a las víctimas:

a. La satisfacción. "Relacionadas con la cesación de violaciones continuadas y la consecución de la verdad sobre los hechos para su divulgación".

b. La no repetición. "Relacionadas con las medidas que deben adoptar los Estados para que no queden impunes las faltas cometidas por sus agentes". 5

En cuanto a la imputación del daño, el Consejo de Estado afirma que en casos como el abordado se deben tener en cuenta los siguientes lineamientos jurisprudenciales:

5 Comisión de Derechos Humanos de las Naciones Unidas, Resolución 2005/35: "Principios y directrices básicos sobre el derechos de las víctimas de violaciones manifiestas de las normas internacionales de derecho". Disponible en: http://ap.ohchr.org/documents/S/CHR/resolutions/E-CN_4-RES-2005-35.doc 
a. La jurisprudencia del Consejo de Estado distingue entre la responsabilidad aplicable a la administración por daños sufridos en el ejercicio del servicio militar obligatorio - y con ocasión del mismo - , de la que surge de aquellos daños padecidos por un integrante de las fuerzas armadas incorporado voluntariamente al servicio.

b. Las personas que prestan el servicio militar obligatorio sólo están obligadas a soportar las cargas que son inseparables a la prestación del servicio, $[\ldots]$ pero no los riesgos anormales o excepcionales. Quienes prestan el servicio en forma voluntaria, [...] asumen todos aquellos riesgos que naturalmente están relacionados con el desempeño de las actividades de la milicia.

c. [...] [En] los daños causados a quien presta servicio militar obligatorio, la imputación se hace con base en la teoría del riesgo excepcional, bajo la óptica de un régimen objetivo de responsabilidad.

d. [...] [En] la responsabilidad frente a quien prestaba sus servicios como voluntario, se entiende que dicha persona es parte en una relación laboral con el Estado, la cual está regida por los derechos y obligaciones relativos a dicho nexo, los cuales se concretan cuando se presentan daños ocurridos con ocasión de la prestación del servicio y en directa relación con el mismo; igualmente, si el daño no se produjo por causa y con ocasión del servicio, pero es imputable a la administración, la responsabilidad deberá establecerse bajo la óptica de la falla del servicio. ${ }^{6}$ 